\title{
Determinants of cognitive dissonance among buyers of consumer durables
}

\section{SACHU ZACHARIAH JOHN AND KRISHNA R. NAIR}

Received : 04.08.2017; Revised : 07.09.2017; Accepted : 21.09.2017

\begin{abstract}
Cognitive dissonance is the term used when there is inconsistency between two cognitions and is recognised by an individual. In the present study the determinants which cause an individualto have cognititve dissonance towards buying of consumer durables are brought out, taking LED TV as the test item.A survey on hundred and twenty consumers of LED TV in the Thrissur Corporation of Kerala state was made. Random sampling method was used to sample the respondents. Its determinants were analysed by means of factor analysis. Out of hundred and twenty respondents seventy respondents have found to experience cognitive dissonance. Out of ten variables and fifty six sub variables examined, seventeen factors such as Family status, Influence of peer group, Trust in the sales man, Education, Religious factors, Information about the product, Market search, Sales promotion, Perception of consumers, Quality of the product, Advertisement, Confidence level on product, Emotion driven, Cash discount, Packaging, Brand loyalty and After sales service were evolved as the major determinants. The methods adopted by the consumers to minimize cognitive dissonance were also analysed by forming indices. 'Will share good qualities of the product with peer group' and 'Confirm the positive aspects with other buyers' were emerged to be the top two steps that will be adopted by the consumers to minimise the cognitive dissonance. The present study will help the sales personnels to identify the major areas that has to be given attention to make possible 'consumer delight'.
\end{abstract}

KEY WORDS : Cognitive dissonance, Consumer durables, LED TV, Determinants of cognitive dissonance, Minimization of cognitive dissonance

How to cite this paper: John, Sachu Zachariah and Nair, Krishna R. (2017). Determinants of cognitive dissonance among buyers of consumer durables. Internat. J. Com. \& Bus. Manage, 10(2) : 205-212, DOI: 10.15740/HAS/IJCBM/10.2/205-212. 